\title{
Pervivencia de estereotipos de género en las imágenes de los libros de texto de música españoles
}

\author{
María del Mar Bernabé Villodre ${ }^{1}$ \\ ORCID: 0000-0001-8983-6602 \\ Desirée García Gil² \\ ORCID: 0000-0002-0591-6873 \\ Vladimir Martínez Bello ${ }^{1}$ \\ ORCID: 0000-0002-3408-9678
}

\section{Resumen}

Los libros de texto musicales, en España, han intentado recoger los cambios legislativos promovidos gubernamentalmente, así como las diferencias en el tratamiento del género, mediante la representación de la mujer como instrumentista. El libro de texto de Música se convierte en una herramienta de difusión de estereotipos que pueden haber perdido vigencia en el mundo musical, pero que no terminan de interiorizarse debido al impacto de la imagen estereotipada publicada. Se han analizado 2.414 imágenes de 47 libros de texto de Música de Educación Primaria de distintas editoriales españolas para la Comunidad Valenciana con el objetivo de mostrar la evolución y presencia de la mujer como instrumentista (de 1992 a 2011). Se recurrió a un análisis de contenido de carácter cuantitativo con el objetivo de determinar los patrones a gran escala de los mensajes transmitidos por las imágenes; y a un análisis cualitativo en el que fueron seleccionadas unas imágenes con base en los resultados del análisis de contenido cuantitativo. Si bien la presencia de la mujer como instrumentista no ha aumentado considerablemente, su representación con instrumentos tradicionalmente masculinos sí ha sufrido un cambio relevante a nivel cualitativo, si se compara con las representaciones masculinas. Así, existe más representación femenina con instrumentos tradicionalmente masculinos; pero, se la sigue representando menos. Todavía queda mucho camino por recorrer para que los libros de texto de educación musical ofrezcan imágenes de instrumentistas que sean respetuosas con la diversidad sexual; de manera que no contribuyan a la perpetuación de estereotipos sexistas.

\section{Palabras clave}

Género - Imagen - Instrumentos musicales - Libros de texto - Educación primaria - Música.

1- Universidad de Valencia, Valencia, España. Contactos: maria.mar.bernabe@uv.es; vladimir.martinez@uv.es.

2- Universidad Complutense de Madrid, Madrid, España. Contacto: desiree.garcia@edu.ucm.es. 


\section{Survival of gender stereotypes in the images of Spanish music textbooks}

\section{Abstract}

Musical textbooks in Spain have tried to capture the legislative changes promoted by the government, as well as the differences in the treatment of gender, through the representation of women as instrumentalists. The Music textbook becomes a tool for disseminating stereotypes that may have lost their validity in the musical world, which however are not completely internalized due to the impact of the published stereotyped image. Analysis included 2,414 images of 47 Primary Education Music textbooks from different Spanish publishers for the Valencian Community whose aim was to show the evolution and presence of women as instrumentalists (from 1992 to 2011). A quantitative content analysis was used in order to determine the large-scale patterns of the messages transmitted by the images; and a qualitative analysis was also conducted in which some images were selected based on the results of the quantitative content analysis. Although the presence of women as instrumentalists has not increased considerably, their representation playing traditionally male instruments has undergone a relevant change on a qualitative level, when compared to male representations. Thus, there is more female representation with traditionally male instruments; but women musicians are still less represented. There is still a long way to go for music education textbooks to offer images of instrumentalists that are respectful of sexual diversity; so that they will no longer contribute to the perpetuation of sexist stereotypes.

\section{Keywords}

Gender - Image - Musical instruments - Textbooks - Primary Education - Music.

\section{Introducción}

La Ley Orgánica 1/1990 (ESPAÑA, 1990), de 3 de octubre, de Ordenación del Sistema Educativo (en adelante, LOGSE), promulgada en España, trajo consigo importantes novedades destinadas a mejorar la situación educativa del país, entre las que destacan la ampliación de la obligatoriedad escolar hasta los 16 años -como forma de disminuir la situación de inactividad profesional de los sectores más jóvenes en edad de trabajar- y el aumento del grado de competencia autonómica. Así, la LOGSE revisó la organización curricular musical y conllevó pérdidas significativas que impidieron una adecuada labor docente musical (MORALES, 2004). Este documento legal que reformuló y reorganizó la Educación Secundaria Obligatoria (en adelante, ESO) y el Bachillerato (en adelante, BACH), respecto a la anterior Ley Orgánica 8/1985 (ESPAÑA, 1985), de 3 de julio, reguladora del Derecho a la Educación (en adelante, LODE), procuró una nueva visión para la estructuración de los libros de texto como fueron la inclusión de referencias a los criterios 
de evaluación y a los objetivos de cada tema, la presencia de más imágenes, etc. (HIDALGO, 2014). Específicamente, la enseñanza musical para Educación Primaria (en adelante, EP) evolucionó, como habrá ocasión de comprobar, desde manuales caracterizados por la presencia mayoritaria de conceptos teóricos y partituras, a la profusión de fotografías y/o dibujos de compositores y/o instrumentos.

En los primeros años del siglo XXI, se promulgaría la Ley Orgánica 2/2006 (ESPAÑA, 2006), de 3 de mayo, de Educación (en adelante, LOE), dentro de una política general interesada en promover políticas de igualdad de género: no en balde, se creó una cartera ministerial de Igualdad (CARRETERO, 2009) y se llevaron a término declaraciones de equidad de género en las editoriales educativas (HAWKINS, 2007). Así, LOGSE y LOE presentaron importantes diferencias, sobre todo, a nivel de preparación del alumnado como competente en distintas áreas: se promulgaron las Competencias Básicas, que marcaron una nueva organización curricular y bibliográfica también para el ámbito musical (GODALL; ANDREU, 2010). En correlación con dichos materiales se pudo evidenciar no tanto un incremento significativo del número de imágenes femeninas, sino un cambio en su aparición con instrumentos de viento-metal o percusión (HIDALGO, 2016).

Aunque desde la década de 1960 se estaban haciendo importantes investigaciones nacionales sobre género y educación musical (VALDEBENITO, 2013), y, especialmente desde una perspectiva más musicológica (VIÑUELA, 2011), el estudio de las representaciones gráficas femeninas quedó un poco descuidado hasta que, desde finales del siglo XX y principios del XXI, empezó a otorgarse mayor importancia a las cuestiones de género (ZERVOUDAKES; TANUR, 1994; DIGÓN-REGUEIRO, 2000; LÓPEZ-NAVAJAS, 2014; HIDALGO, 2016). Así, con anterioridad a la LOGSE, en los libros de texto, la figura femenina aparecía representada más veces como instrumentista de viento-madera, bien como flautista o clarinetista, que como instrumentista de viento-metal (DIGÓN-REGUEIRO, 2000), bien como trompetista o tubista. Este hecho se alejaba de una realidad de mujeres instrumentistas de viento-metal que se estaba reflejando, por ejemplo, en las Sociedades de Música Valencianas (MÁÑEZ, 2015). En este sentido, es notable el detrimento de la repercusión historiográfica de compositoras o directoras de orquesta (KOZA, 1992; DIGÓN-REGUEIR0, 2000), al mismo tiempo que resulta significativa la disminución de la representación de las mujeres con instrumentos (y con determinados instrumentos) en relación con la presencia de los hombres (KOZA, 1994). El análisis de la realidad de género respecto a la utilización de los instrumentos musicales se ha centrado desde el análisis de los libros de texto porque se ha creado una dependencia de este medio y un olvido sistemático del tratamiento integrado del currículo y de sus temas transversales (FERNÁNDEZ, 2008); así, el manual se ha convertido en la herramienta desde la que parten las actividades, explicaciones y otras actividades musicales. De hecho, con la LOGSE, acentuándose todavía más con la LOE, dichos materiales debían alejarse de las posturas tradicionalistas ante el hecho musical, que contribuian a la perpetuación de determinados cánones musicales (DIGÓN-REGUEIRO, 2000), a la pervivencia de arquetipos tradicionales masculinos-femeninos (PELLEJERO; TORRES, 2011), y, en definitiva, a eliminar la posibilidad de una práctica docente compensatoria (LOIZAGA, 2005). 
A su vez, las disposiciones legislativas de los conservatorios de Música que, a principios del siglo XX, sólo admitían la presencia de féminas en las cátedras de Piano, Canto o Pedagogía Musical (HERNÁNDEZ, 2011), fue el punto de arranque para que la mujer accediese como docente y alumna a otras especialidades musicales, habitualmente reservadas para varones: desde el año 2016, el Conservatorio Superior de Música de Castellón cuenta con una mujer en la Cátedra de Trompa.

Todas las leyes citadas tendrían su reflejo, en mayor o menor medida, en los decretos y órdenes de las distintas comunidades autónomas y, por tanto, en los libros de texto de sus respectivas secciones editoriales. Dentro de éstas, cabe tener en cuenta el caso de la Comunidad Valenciana, cuya evolución en la integración de las desigualdades de género tanto en grupos musicales oficiales como en centros educativos específicamente musicales no ha corrido paralelo a su reflejo en los libros de texto. Entonces, atendiendo a las consideraciones de la denominada Tercera Ola en los estudios de género (LOIZAGA, 2005), esta investigación se ha centrado en mostrar las diferencias de representación entre mujeres y hombres en las imágenes de los libros de texto, en cuanto a la utilización de unos u otros instrumentos musicales. Así, se pone énfasis en lo que Loizaga (2005) ha venido a denominar relectura de un fenómeno cultural fundamental como es la interpretación musical, de la que participan mujeres y hombres en (supuesta) igualdad de condiciones.

Teniendo en cuenta dicho contexto, esta investigación tiene como objetivo principal estudiar la representación de la mujer instrumentista en los libros de texto de las principales editoriales valencianas, debido a la tradición bandística de dicha región, caracterizada por la aceptación del músico sin distinciones de género. Este objetivo principal se enmarcaría en uno de los principales ámbitos de investigación de los estudios de género en la educación musical: la investigación sobre el proceso de Enseñanza/ Aprendizaje (LOIZAGA, 2005), en donde el libro de texto sigue siendo una herramienta fundamental y, por tanto, dependiente de constantes deconstrucciones e intervenciones. A nivel secundario, sus objetivos se han centrado en: mostrar la evolución de la mujer en determinados instrumentos de tradición masculina; y comprender los motivos que han podido determinar la evolución mayor o menor de dichas representaciones femeninas.

\section{Fundamentación teórica}

En epígrafes siguientes, se presenta el marco teórico que vendría a justificar la investigación realizada, dotándola de sentido en el contexto educativo español; aunque, como podrá comprobarse seguidamente, parece ser una triste realidad que afecta a diferentes países del mundo, que también presentan estereotipos de género en sus libros de texto musicales.

\section{Mujer, libro de texto e imágenes}

La publicación de libros de texto de mano de mujeres ha sido una de las vías en la que éstas encontraron una oportunidad de actuación dentro del extenso ámbito de la educación musical. A este respecto, Wieland (2009) pone el acento en el hecho de que 
ya en el siglo XIX, las principales colecciones de manuales de música norteamericanas -National Music Course, Normal Music Course, Natural Music Course- dirigidas por hombres, contaban con féminas en la publicación y traducción de textos. La misma investigadora señala que, actualmente, las labores de edición de manuales docentes y obras científicas y musicales han favorecido un sustancial incremento de los puestos $\mathrm{y}$ funciones necesarios para su elaboración y publicación $\mathrm{y}$, por ende, del número de féminas que pueden trabajar en ellos. Sin embargo, ¿cómo se representa el segundo sexo en los libros de texto actuales?

Ya en 2007, Hawkins manifestó que los estudios sobre género llevados a cabo en libros de texto desde los años sesenta llamaron la atención sobre que, en estos materiales, los roles, las imágenes y los textos que versaban sobre caracteres masculinos abundaban notablemente sobre los femeninos, transmitiendo por tanto un discurso androcéntrico. Así, el mismo investigador elaboró un estudio sobre el tratamiento del género y el sesgo de sexo que pueden encontrarse en dos libros de textos corales para Educación Secundaria -Choral Connections Beginning Level 1 Treble Voices y Choral Connections Beginning Level 1 Tenor-Bass Voices- analizando los textos de cincuenta y cinco canciones disponibles en las diferentes ediciones para chicos y chicas. De esta manera, puso de manifiesto que se apreciaba una mayor proporción de personajes masculinos que femeninos en todas las canciones, al tiempo que los primeros se identificaban con adjetivos como "[...] asertivo, masculino [...], aventurero y confiado en sí mismo" mientras que las segundas se describían como "cariñosas, cuidadosas, tiernas y comprensibles" (HAWKINS, 2007, p. 5). En correspondencia, se nombraron dos compositoras y cuarenta y tres compositores, al tiempo que el número de artistas, músicos y escritores fue significativamente mayor en el caso de ellos que en los de ellas.

Algo similar ocurre en los manuales sobre literatura española dentro del ámbito de la Educación Secundaria, que revelan que los volúmenes especializados sobre literatura para dicho nivel muestran un fuerte cercenamiento de presencia femenina que termina produciendo la consideración de ciudadanas de segunda y el falseamiento de la memoria cultural (LÓPEZ-NAVAJAS; QUEROL, 2014).

Además de la presencia o ausencia de las aportaciones sociales, humanísticas y científicas de las mujeres en los libros de texto, en la línea de las investigaciones compensatorias desarrolladas durante la Segunda Ola, debe tenerse en cuenta el estudio de las imágenes de éstas en dichos materiales -tal como plantea la presente investigación acorde con la Tercera Ola y una de sus propuestas de investigación centradas en la crítica de las corrientes academicistas tradicionales (LOIZAGA, 2005)- pues, más allá de su valor estético (VALLS, 2007) la inherente función propagandística y discursiva de los signos iconográficos conlleva la transmisión de una serie de valores y representaciones sociales que deben ser tenidas en cuenta (PARRA, 2009; GONZÁLEZ; TÁBOAS; REY, 2010), puesto que todo producto artístico (las imágenes incluidas en los libros de texto no pueden dejar de considerarse como tales, al ser fruto de la creación artística de un diseñador/artista) tiende a representar en mayor o menor medida y de uno $u$ otro modo, una realidad circundante. Aunque, en esta investigación no nos interesa tanto incidir en el valor social y cultural o estético de las imágenes (VALLS, 2007), sino en el hecho de que muestran 
una realidad de género que no puede obviarse, pero sí debe cambiarse. El libro de texto se convierte, entonces, en un mecanismo invisible de transmisión y refuerzo de desigualdades (TERRÓ; COBANO-DELGADO, 2008), situación que podría evitarse con un adecuado uso de la imagen de estos.

En este sentido, Sadeq (2016) analizó cómo la mujer es representada en los libros de texto de Primaria de Jordania a través de ilustraciones, actividades y textos. A partir de los primeros, se enfatizó que todavía era necesario: aumentar el número de imágenes en el que se subraya el derecho de la mujer al trabajo y su acceso en equidad a la sociedad y distribuir de manera justa las ocupaciones familiares entre sexos. Según la investigadora, dicho énfasis debe llevarse a cabo a través de la mejora y el cuestionamiento del currículum nacional, prestando especial atención a la educación cívica. Aunque la mujer jordana está representada dentro de unos estrechos límites patriarcales, en los libros de texto de Historia de EE.UU., Shocker y Woyshner (2013) señalaron la escasez de imágenes de mujeres afroamericanas.

Desde el punto de vista nacional, los estudios sobre sexismo en los libros de texto datan de finales de los ochenta (RODRÍGUEZ, 2004) y la mayoría de los esfuerzos se han llevado a cabo desde otras materias curriculares diferentes a la musical (PRO; PRO, 2011; LÓPEZ-NAVAJAS, 2014; GÓMEZ-PINTADO; MARCELLÁN, 2017). Así, Cerrón y CobanoDelgado (2008) estudiaron 1.062 imágenes aparecidas en los manuales -Conocimiento del Medio Natural, Social y Cultural, Lengua Castellana y Literatura y Matemáticas- de EP de las editoriales Anaya, Everest y SM, para conocer el papel otorgado a la mujer e indagar en los valores que se transmiten. Por su parte, concluyeron que: la presencia de figuras masculinas sigue siendo más elevada que la de las femeninas; ellos se relacionan con los espacios públicos y ellas con los privados; las mujeres se asocian, generalmente, con actitudes alegres; se hace más alusión a profesiones referidas a los hombres que a las mujeres y es más fácil encontrar representaciones masculinas realizando tareas domésticas, que de mujeres en puestos de responsabilidad.

Por su parte, Moya y otros autores (2013) recogieron y estudiaron 997 imágenes de nueve libros de texto de Educación Física para EP -editados por Inde, Paidotribo, Bruño, Anaya y Serbal- con el fin de comprobar la presencia o ausencia de estereotipos: pusieron de manifiesto la existencia de un modelo masculino dominante, aunque ambos géneros se mostraban en actividades que implicaban ciertas habilidades físicas.

Son muchos los investigadores que señalan cierto prejuicio sexista de la sociedad, recogido en los libros de texto y, puesto que éstos son el material predominante del aula, regulan las prácticas educativas (KOZA, 1992; DIGÓN-REGUEIRO, 2000). Así, no es de extrañar que también dicten las normas no escritas en la selección de un instrumento musical, puesto que niños y niñas aprenden a través de las imágenes y las toman como reflejo fidedigno de su realidad externa: si un alumno aparece representado siempre con una trompeta y una alumna con una flauta travesera, será difícil realizar una elección diferente porque las imágenes contribuyen a perpetuar estos estereotipos (KOZA, 1992): Pellejero y Torres (2011) consideran que el currículo oculto reproduce modelos discriminatorios y el currículo explícito refleja escasamente la igualdad, lo que se traduce en situaciones de igualdad plasmada juntamente con otras discriminatorias. 
En definitiva, aun cuando la investigación ha declarado la competencia de la contribución femenina en diferentes ámbitos del saber -literatura (SIMÓN, 2006), música (ÁLVAREZ, 2008), arte (MUÑOZ, 2004) y pensamiento (GLEICHAUF, 2010)-, su representación en los libros de textos actuales todavía necesita una valoración crítica.

\section{La influencia de la tradición instrumental de las Bandas de Música y su reflejo en los libros de texto}

En España, el fenómeno de las Bandas de Música es característico de todas las comunidades autónomas (CLARES, 2005; AYALA, 2013). Ahora bien, pueden hacerse distinciones significativas si se tienen en cuenta el número de poblaciones y Bandas de Música por cada una de ellas: por ejemplo, frente a las veinticinco federadas con que cuenta la Comunidad de Madrid, la Región de Murcia presenta veinte, quintuplicando este número la Comunidad Valenciana con 544 siendo, por tanto, uno de los territorios con mayor número de Bandas de Música federadas por población, sin contar las charangas (OLIVER, 2013). Esta tradición se ha reflejado en la importante producción del repertorio conocido como Música festera (PERALTA, 1995) y de música especialmente producida para sus festivales internacionales de música (MAS, 1979).

En cuanto a la cuestión de género y de acuerdo con Koza $(1992,1994)$ y DigónRegueiro (2000), determinados instrumentos eran reservados para hombres y otros para mujeres: esta tradición supuso la pervivencia en los libros de texto de determinados estereotipos que se observaban en las Bandas, como era la elección del instrumento musical atendiendo al género. En este sentido, Cabanes (2008) ha señalado que, debido a la tradición sociocultural sexista, los varones tocan instrumentos de mayor tamaño y peso (tuba y bombardino), mientras que las féminas se especializarían en otros más pequeños y menos pesados (flautín o flauta); y, Sansaloni (2017) ha mostrado que todavía hay instrumentos que tienen un predominio masculino superior al 90\% (trombón, trompeta y tuba), siendo más numerosa la presencia femenina en instrumentos como flauta travesera. En esta línea, los datos de la Federación de Sociedades Musicales de la Comunidad Valenciana (ALMENAR, 2012) mostraban que el 47\% de los miembros de las Bandas eran mujeres: ellos tocando trompetas y trombones, ellas flautas o clarinetes.

Especialistas como Abeles y Porte (1978), Griswold y Chroback (1981), Zervoudakes y Tanur (1994), y Conway (2000) ya investigaron sobre la relación entre elección de instrumentos musicales y estereotipos de género, que vendrían a justificar la necesidad de comprobar cuánto se ha avanzado en el siglo XXI. Aunque estos investigadores mencionen muchos factores como determinantes en la selección del instrumento, las connotaciones sexuales asociadas a ellos siguen vigentes y tienen más influencia que cualquier otro aspecto (OYA; HERRERA, 2013). Para llegar a modificar la tradición de género en la selección del instrumento, y, aunque se evidencia cierto cambio (VAILLO, 2016), hay que hacer hincapié en la formación del profesorado de Música desde una perspectiva de género (DÍAZ, 2005), encaminada a evitar el reforzamiento de roles sexuales históricamente asociados para favorecer una mayor igualdad entre los instrumentistas. 


\section{Diseño y metodología}

Seguidamente, se detallan los diferentes pasos seguidos en la realización de esta investigación. A lo largo de este epígrafe, pueden encontrarse las diversas herramientas utilizadas a lo largo del proceso investigador: cuestionario validado por expertos y la documentación enviada a los especialistas en el ámbito de estudio para que procediesen a la validación de la herramienta principal de trabajo de esta investigación.

\section{Selección de libros de texto y de unidades de registro}

Libros de texto seleccionados

Las imágenes analizadas pertenecen a manuales de todos los ciclos de EP, en sus ediciones realizadas para la Comunidad Valenciana, entre 1992 y 2011. Son 14 editoriales de gran trayectoria y relevancia en España (PÉREZ, 2001): Santillana Primaria, Voramar Santillana, Santillana Proyecto La Casa del Saber, Ediciones Abril, Pearson Alhambra, Bruño, Octaedro, Real Musical, Magisterio Casals, Edebé, Edelvives, SM Música Al Compás, SM En Clave de Sol y Anaya. Así, se han estudiado 47 libros repartidos en dos períodos: el primero, marcado por la LOGSE; y, el segundo, por la LOE.

El criterio de selección de editoriales editoriales viene determinado por la disponibilidad al acceso de las fuentes dentro de la biblioteca universitaria donde se lleva a cabo la investigación: las existencias de materiales de la biblioteca del centro universitario de pertenencia. No obstante, debe señalarse que dicha instalación contaba con gran parte de las casas editoriales más utilizadas en la Comunidad Valenciana y resto del territorio nacional, tal como ha mostrado Gallego (2015) en su análisis desarrollado alrededor de las editoriales de Música. Fue esto lo que llevó a no incluir posibles diferencias al respecto entre editoriales y centrar la importancia del análisis de una forma más global en cuántas mujeres y con qué instrumentos aparecen representadas, entre otras cuestiones que se expondrán seguidamente.

\section{Selección de las unidades de registro}

En este estudio, las unidades de registro fueron las imágenes representadas en los libros de texto seleccionados. Se han considerado escenas que comprendían distintas figuras humanas (tanto masculinas como femeninas) relacionadas por la acción desarrollada en la actividad específica mostrada en la ilustración; de modo que, se ha realizado un cómputo observacional de un total de 2.414 representaciones gráficas. La población total de unidades de registro estuvo compuesta por 885 imágenes representativas de niñas y mujeres adultas, de una población total de 47 libros de texto en los dos periodos de tiempo. De este total de unidades de registro, se procedió a seleccionar una muestra, con el fin de valorar la fiabilidad del sistema de categorías con un grupo observacional. Se calculó el tamaño de la muestra, utilizando un intervalo de confianza de $+7 \%$, con un nivel de confianza del 95\%, y el total, la muestra estuvo compuesta por 161 imágenes. No se tuvieron en cuenta alusiones gráficas de animales con características humanas, 
etc., porque su estudio quedaba alejado de las pretensiones de esta investigación. Si bien, es cierto que éstos sirven para confirmar la importancia de la presencia del elemento visual gráfico (PRENDES, 1998), que aleja al manual de educación musical del tradicional concepto teórico y práctico interpretativo (sin imágenes de la vida cotidiana, por ejemplo, sólo con fotografías de compositores representativos y partituras).

\section{Análisis de las unidades de registro}

En esta investigación se utilizaron dos perspectivas para analizar las imágenes. Por una parte, se realizó un análisis de contenido de carácter cuantitativo con el objetivo de determinar los patrones a gran escala de los mensajes transmitidos por las imágenes. Y, por otra, se procedió a realizar un análisis cualitativo en el que fueron seleccionadas unas imágenes con base en los resultados del análisis de contenido cuantitativo.

\section{Análisis de contenido}

El análisis de contenido es una técnica utilizada para determinar los mensajes que transmiten unidades de registro, como el texto y las imágenes, a través de un sistema de codificación de categorías e indicadores (HSIEH; SHANNON, 2005). En el ámbito del análisis de libros de texto de educación musical, la técnica de análisis de contenido ha sido utilizada previamente.

\section{Creación del sistema de categorías e indicadores}

El sistema de categorías, compuesto por una serie de categorías e indicadores, fue elaborado por el grupo de investigación teniendo en cuenta investigaciones previas nacionales e internacionales sobre el análisis de libros de texto de distintas áreas. Además, para la elaboración de sus categorías, se trató de reflejar la realidad educativa marcada por la legislación: es decir, no sólo la división en ciclos por edades, sino también el tipo de actividades musicales que constituían el currículo educativo en la LOGSE y la LOE, reflejado en los libros de texto. Así, se ofrece una escala de entre 3 y 7 tipos de respuesta a los 8 ítems que lo componen, indicadores representativos de los factores determinantes de la Presencia de la mujer instrumentista en los libros de texto de Educación Primaria. Sólo el último es abierto, puesto que corresponde al espacio destinado a escribir el nombre del instrumento representado para facilitar la cuantificación de éste con la figura femenina y permitir la comparación de los resultados obtenidos con la figura masculina.

Debe tenerse en cuenta que la inclusión de un ítem centrado en el tipo de representación (imagen o fotografía) vino determinado por las consideraciones de DigónRegueiro (2000), quién señaló que en los libros de texto la mujer con instrumentos era más veces representada como un dibujo que el hombre, que aparecía principalmente en el formato de fotografía. En cuanto al estilo musical, se partió de la clasificación habitual utilizada en los libros de texto, en función del tipo de figura y los atributos representados. Por último, el tipo de instrumento se organizó también de acuerdo con la clasificación 
presente en los libros de texto y manuales musicales (REMNANT, 2002). Las distintas categorías básicas y subcategorías del instrumento fueron:

Tabla 1- Categorías y subcategorías del instrumento

\begin{tabular}{|c|c|c|}
\hline Categoría & Indicadores & Descripción \\
\hline Nivel educativo & $\begin{array}{l}1^{\circ} \text { ciclo } \\
2^{\circ} \text { ciclo } \\
3^{\circ} \text { ciclo }\end{array}$ & Nivel del libro \\
\hline Foto o imagen & $\begin{array}{l}\text { Foto } \\
\text { Imagen }\end{array}$ & Imagen es: fotografía o dibujo \\
\hline Edad & $\begin{array}{c}\text { Infancia } \\
\text { Adolescencia } \\
\text { Adultos } \\
\text { Adultos mayores }\end{array}$ & $\begin{array}{l}\text { Presentan edades entre: 0-6 años, 6-12 años, 13-19 } \\
\text { años, 20-40 años 0 50-80 años }\end{array}$ \\
\hline Grupo & $\begin{array}{l}\text { Sola } \\
\text { Niña-niña } \\
\text { Mixto } \\
\text { Grupo con adulto } \\
\text { Grupo chicas }\end{array}$ & $\begin{array}{l}\text { Imagen muestra: persona sola, niña con niña, grupo } \\
\text { de niñas, grupo mixto; grupo con adulto }\end{array}$ \\
\hline Tipo de actividad desarrollada & $\begin{array}{l}\text { Amateur } \\
\text { Profesional }\end{array}$ & $\begin{array}{c}\text { Imagen muestra una o más personas cuyas } \\
\text { características representan su trabajo en grupo } \\
\text { musical o en el aula }\end{array}$ \\
\hline Prácticas musicales & $\begin{array}{l}\text { Orquesta } \\
\text { Banda } \\
\text { Grupos de cámara } \\
\text { Solista } \\
\text { Coro } \\
\end{array}$ & $\begin{array}{l}\text { Imagen muestra: conjunto instrumental } \\
\text { predominantemente de instrumentos de cuerda, } \\
\text { conjunto instrumental predominantemente de } \\
\text { instrumentos de viento, grupo vocal dirigido, pequeño } \\
\text { grupo instrumental sin director, o instrumentista sólo }\end{array}$ \\
\hline Estilo musical & $\begin{array}{c}\text { Música académica } \\
\text { Música tradicional } \\
\text { Música popular } \\
\text { Interpretación musical sin partitura }\end{array}$ & $\begin{array}{l}\text { Figuras humanas aparecen: vestidas formalmente, } \\
\text { vestidas tradicionalmente, vestimenta informal, } \\
\text { improvisación, lección musical }\end{array}$ \\
\hline Tipo de instrumento & $\begin{array}{c}\text { Viento-madera } \\
\text { Viento-metal } \\
\text { Cuerda frotada } \\
\text { Cuerda percutida } \\
\text { Cuerda pulsada } \\
\text { Voz } \\
\text { Percusión }\end{array}$ & $\begin{array}{c}\text { Instrumento representado pertenece a sección: } \\
\text { viento-madera, viento-metal, cuerda frotada, cuerda } \\
\text { percutida, cuerda pulsada, persona con boca abierta } \\
\text { y gesto manual acompañando, instrumento de sonido } \\
\text { indeterminado/determinado }\end{array}$ \\
\hline
\end{tabular}

Fuente: Elaboración propia.

Una vez elaborado el sistema de categorías e indicadores, fue sometido a juicio de expertos (profesorado universitario, de Enseñanzas Artísticas y de ESO), a través de un cuestionario con escala de Likert, a través del cual se recogió su opinión. 
Tabla 2- Documento de evaluación del cuestionario utilizado (expertos): tipo de instrumento

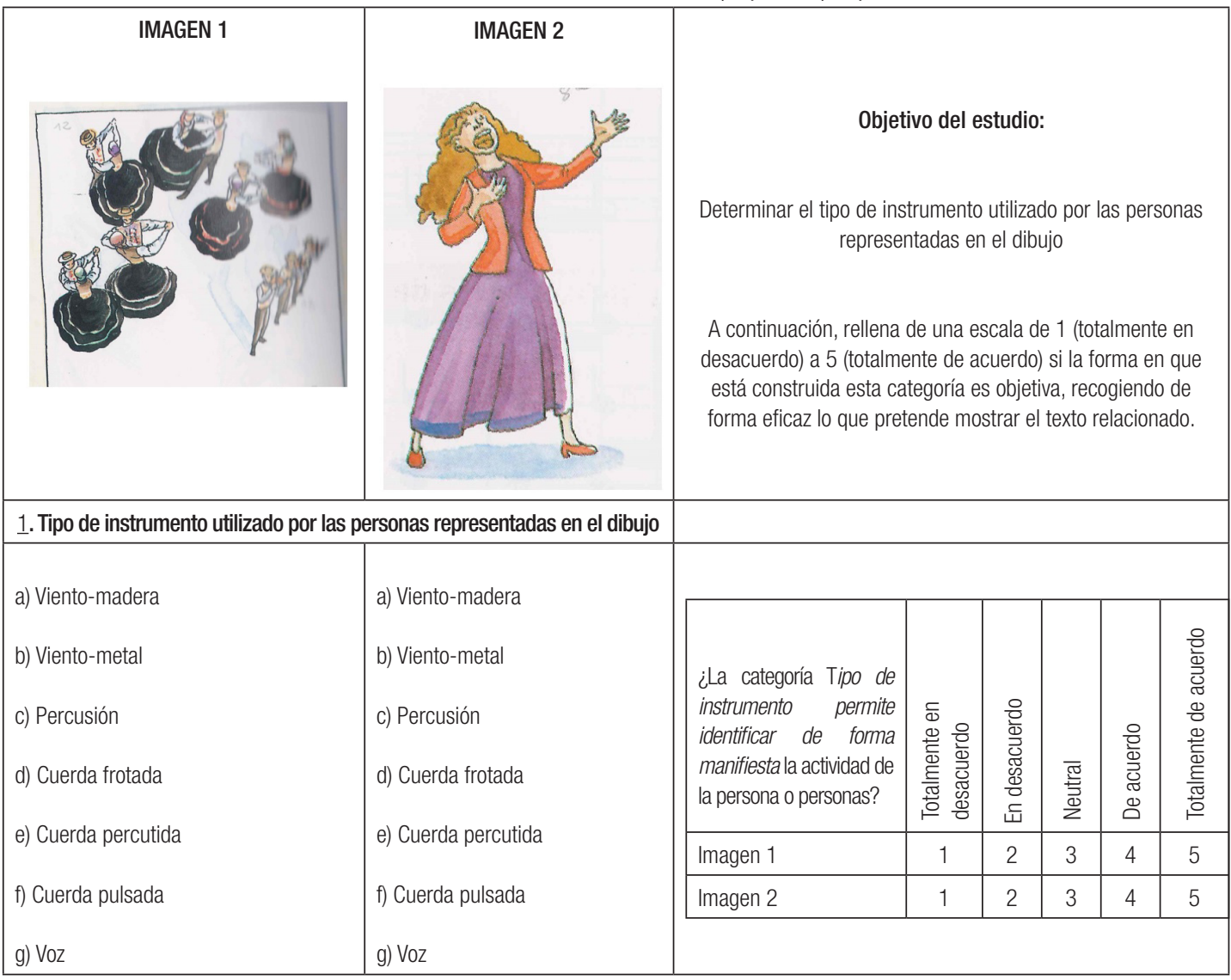

Espacio para observaciones:

- Viento-madera: El instrumento representado pertenece a la sección de viento-madera.

- Viento-metal: El instrumento representado pertenece a la sección de viento-metal.

- Percusión: El instrumento representado pertenece a las secciones de sonido determinado o sonido indeterminado.

- Cuerda frotada: El instrumento representado pertenece a la sección de cuerda frotada.

- Cuerda percutida: El instrumento representado pertenece a la sección de cuerda percutida.

- Cuerda pulsada: El instrumento representado pertenece a la sección de cuerda pulsada.

- Voz: El instrumento representado es una persona con la boca abierta y algún gesto de brazos y manos acompañando.

Fuente: Elaboración propia.

Una vez recibidas sus observaciones, el sistema de categorías fue reelaborado, y supuso la adecuación de algunos ítems de las distintas variables a las necesidades de la temática investigada, facilitándose la expresión de unos y concretándose otros. 
Tabla 3- Instrumento de extracción de información de las imágenes

\begin{tabular}{|c|c|c|c|c|c|c|c|c|}
\hline $\begin{array}{c}\text { Nivel } \\
\text { educativo }\end{array}$ & $\begin{array}{l}\text { Foto } 0 \\
\text { imagen }\end{array}$ & Edad & Grupo & $\begin{array}{c}\text { Tipo de } \\
\text { actividad } \\
\text { desarrollada }\end{array}$ & $\begin{array}{l}\text { Prácticas } \\
\text { musicales }\end{array}$ & $\begin{array}{l}\text { Estilo } \\
\text { musical }\end{array}$ & $\begin{array}{c}\text { Tipo } \\
\text { instrumento }\end{array}$ & $\begin{array}{c}\text { Instrumento } \\
\text { concreto }\end{array}$ \\
\hline $\mathrm{N}^{\circ}$ IMAGEN & $\begin{array}{l}\text { 1. } 1^{\circ} \text { ciclo } \\
\text { 2. } 2^{\circ} \text { ciclo } \\
\text { 3. } 3^{\circ} \text { ciclo }\end{array}$ & $\begin{array}{l}\text { 1. Foto } \\
\text { 2. Imagen }\end{array}$ & $\begin{array}{l}\text { 1. Infancia } \\
\text { 2. Adolescencia } \\
\text { 3. Adultos } \\
\text { 4. Adultos } \\
\text { mayores. }\end{array}$ & $\begin{array}{l}\text { 1. Sola } \\
\text { 2. Niña-niña } \\
\text { 3. Mixto } \\
\text { 4. Grupo con } \\
\text { adulto } \\
\text { 6. Grupo } \\
\text { chicas }\end{array}$ & $\begin{array}{l}\text { 1. Amateur } \\
\text { 2. Profesional }\end{array}$ & $\begin{array}{l}\text { 1. Orquesta } \\
\text { 2. Banda } \\
\text { 3. Grupos } \\
\text { de cámara } \\
\text { 4. Solista } \\
\text { 5. Coro }\end{array}$ & \begin{tabular}{|} 
1. Música culta \\
2. Música \\
tradicional \\
3. Música \\
popular \\
4. Otra
\end{tabular} & $\begin{array}{l}\text { 1. Viento-madera } \\
\text { 2. Viento-metal } \\
\text { 3. Percusión } \\
\text { 4. Cuerda frotada } \\
\text { 5. Cuerda } \\
\text { percutida } \\
\text { 6. Voz } \\
\text { 7. Cuerda } \\
\text { pulsada }\end{array}$ \\
\hline
\end{tabular}

Fuente: Elaboración propia.

\section{Procedimiento de análisis de contenido cuantitativo}

Como fue señalado previamente, para valorar la fiabilidad del sistema de categorías, se seleccionó una muestra representativa, utilizando un intervalo de confianza de $+7 \%$, con un nivel de confianza del 95\%. La muestra estuvo compuesta por 161 imágenes. El grupo observacional estuvo formado por la autora principal de este trabajo y un observador independiente, respetándose el mínimo de personas para la codificación en el marco de un análisis de contenidos (NEUENDORF, 2011). Se numeraron todas las imágenes y se extrajeron al azar en base a una tabla de números aleatorios. Previamente, el grupo observacional fue entrenado sobre las categorías e indicadores sin transmitir el objetivo o las hipótesis del estudio. Se utilizaron dos sesiones de observación, realizadas de forma independiente entre observadores, con una duración aproximada cada una de dos horas. En estas sesiones, las imágenes fueron puestas sobre la mesa por otro miembro del grupo y cada observador, de manera independiente, seleccionó un indicador por cada categoría.

Una vez recogidas las observaciones independientes se construyeron tablas de frecuencias y porcentajes de las respuestas, por pregunta y por observador, y se aplicó el índice Kappa de Fleiss, que corresponde a una medida de acuerdo cuando se tienen dos observadores y se determinó la hipótesis nula de no acuerdo entre los evaluadores. Los valores del índice Kappa para las categorías personales y de prácticas musicales fueron las siguientes. Para las categorías personales: edad, $\mathrm{k}=0.85$; agrupación, $\mathrm{k}=0.9$. Para las categorías vinculadas con las prácticas musicales: estilo musical, $\mathrm{k}=0.7$; perfil profesional, $\mathrm{k}=0.65$; tipo de práctica desarrollada, $\mathrm{k}=0.7$; tipo de actividad desarrolla, $\mathrm{k}=0.78$; estilo utilizado, $\mathrm{k}=0.64$. El resto de las categorías se utilizaron con carácter descriptivo. Una vez calculada la congruencia, la autora principal de la investigación analizó individualmente el total de imágenes restantes. Posteriormente, los datos fueron 
exportados al programa SPSS (Versión 20) para su posterior análisis. Los índices de acuerdo fueron considerados de grado de acuerdo sustancial, basados en la clasificación de Landis y Koch (1977).

\section{Análisis complementario cualitativo de las imágenes}

\section{Criterios del análisis cualitativo}

Una vez realizado el análisis cuantitativo de contenido, y una vez detectadas las principales tendencias de los mensajes respecto a la representación de la mujer en ambos periodos de tiempo, se procedió a realizar un análisis cualitativo complementario, a través de una lectura crítica de un grupo de imágenes. Se tuvieron en cuenta diferentes variables cualitativas, sobre las que se establecieron rangos o posiciones sin posibilidad de establecer diferencias numéricas precisas (DEL RÍO, 2003), como forma de complementar los datos cuantificados: el tamaño del instrumento con que fueron representadas las mujeres, en cuanto a peso y altura; la presión de la columna de aire que cada instrumento requería; la presencia física requerida por cada instrumento de percusión, así como la destreza óculo-manual y psicomotora fina; y la mayor resistencia requerida para la interpretación, muy relacionada con la presión de la columna de aire.

No se consideró relevante la posición corporal respecto al instrumento; ya que, ante la interpretación instrumental la posición debería ser la misma: peso repartido entre ambos pies, piernas separadas para equilibrar el cuerpo; y, sentados, piernas cerradas con pies apoyados en el suelo. La postura puede considerarse suficientemente neutra como para no recurrir a diferenciaciones por género, que, en este caso, ni siquiera se contemplarian como una opción: Navia y otros autores (2007) no han referenciado diferencias entre sexos a la hora de detectar lesiones porque puedan presentarse posturas diferenciadas entre hombre-instrumento o mujer-instrumento.

\section{Procedimiento del análisis cualitativo}

Para ello, la investigadora se centró en la actitud y comportamiento de los personajes representados (Figuras 1, 2 y 3). En primer lugar, se detectaron los principales elementos a través de una primera lectura, y posteriormente, se construyó un conjunto de preguntas para ayudar a la lectura crítica de las imágenes: qué forma y peso tiene el instrumento, la dificultad de su manejo, relación tamaño-presión columna de aire, resistencia de la columna de aire y muscular ante la interpretación. 
Figura 1- Representación femenina de cantante

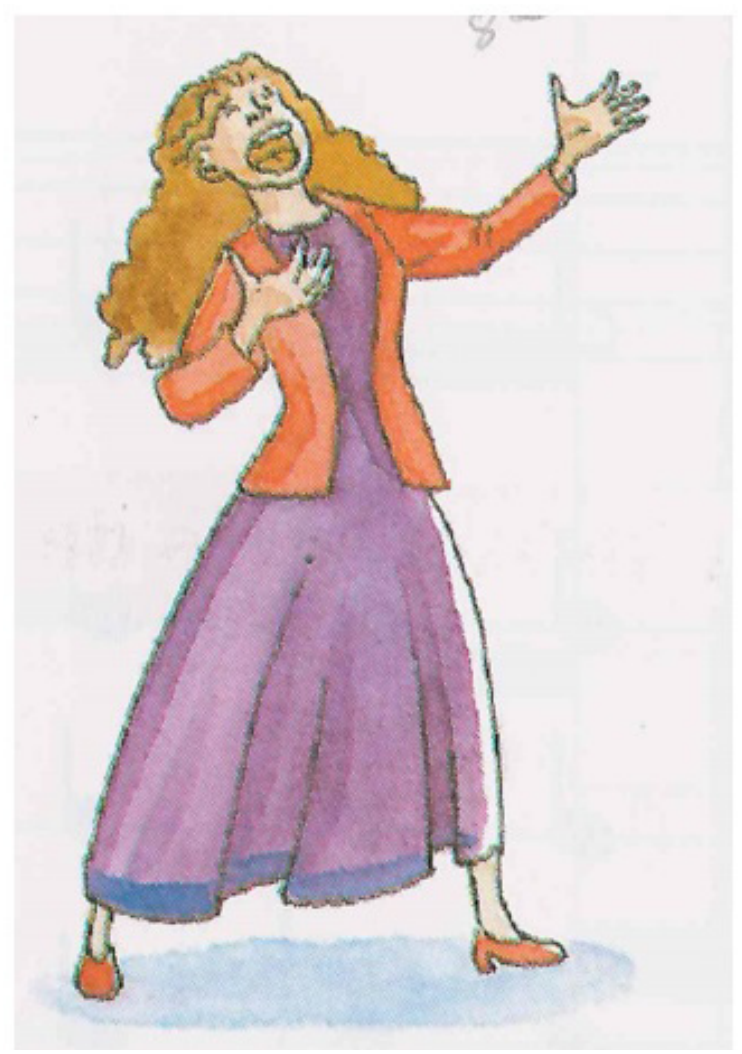

Fuente: Extraída de editorial Santillana.

Figura 2- Representación masculina de trompetista

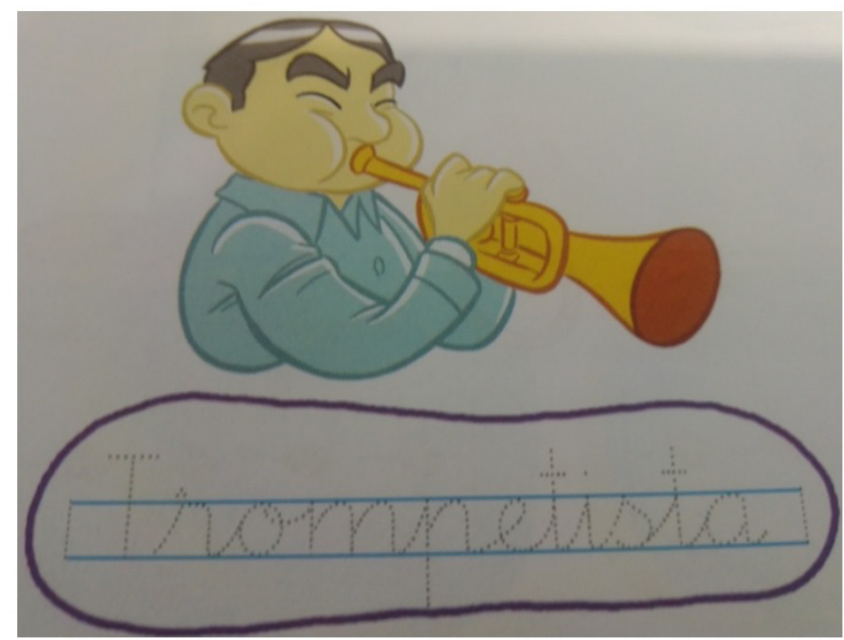

Fuente: Extraída de editorial Anaya. 
Figura 3- Representación masculina de percusionista

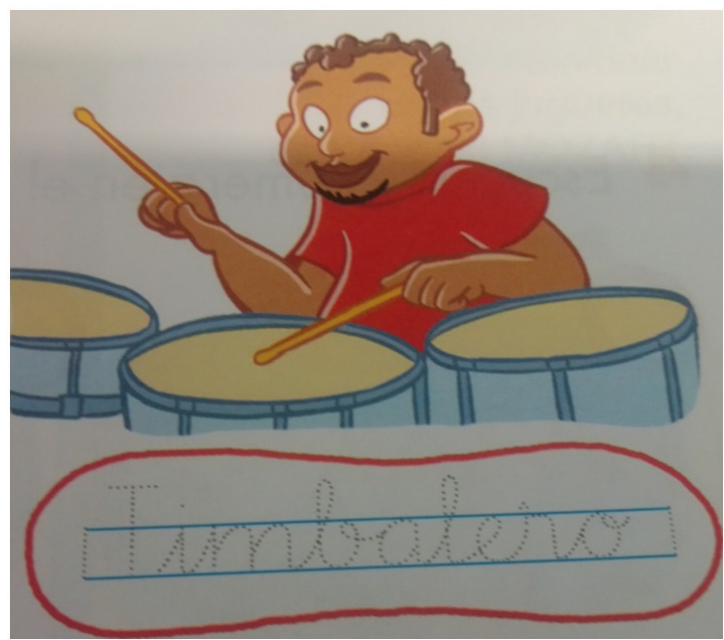

Fuente: Extraída de editorial Anaya.

Con base en la contestación de estas preguntas, se reelaboró la lista de actitudes y comportamientos realizada previamente y se construyeron categorías cualitativas para reforzar los datos numéricos y contextualizarlos. Éstas fueron: tamaño y peso del instrumento, presión de la columna de aire, presencia física para la interpretación, mayor destreza óculo-manual, resistencia que precisan ante la interpretación conjunta. Finalmente, las interpretaciones de la investigadora principal fueron contrastadas con otros miembros del grupo, con el objetivo de señalar los matices, acuerdos y distorsiones de las imágenes analizadas.

\section{Análisis estadístico}

Se utilizó una estadística descriptiva de cada categoría y para la estadística inferencial, se utilizó el estadístico chi-cuadrado para establecer la independencia entre ellas. Se construyó una tabla de contingencia por cada periodo de tiempo, frente a la categoría de edad. Posteriormente, se construyeron tres tablas de contingencia entre las categorías periodo de tiempo frente a las categorías (composición del grupo, familias instrumentales e instrumentos musicales).

A continuación, se utilizaron los estadísticos chi-cuadrado con el objetivo de encontrar diferencias significativas entre las categorias previamente señaladas. Se aceptaron las diferencias con valores de probabilidad inferior a 0.05. Se utilizó el programa SPSS versión 19 para el análisis estadístico.

\section{Resultados}

Los datos obtenidos muestran un incremento significativo de las mujeres frente a las niñas: en concreto, un 22,1\% frente a un 31,3\%. 
Tabla 4- Distribución de la presencia femenina en los dos periodos de tiempo 1992-2006 respecto a la edad

\begin{tabular}{|c|c|c|c|}
\hline & & Niñas & Mujeres \\
\hline \multirow{2}{*}{ LOGSE } & Frecuencia & 341 & 97 \\
\hline & $\%$ & $78 \%$ & $22 \%$ \\
\hline \multirow{2}{*}{ LOE } & Frecuencia & 307 & 140 \\
\hline & $\%$ & $69 \%$ & $31 \%$ \\
\hline
\end{tabular}

Fuente: Elaboración propia.

También, se han obtenido resultados interesantes en cuanto a la distribución de la presencia femenina en los períodos investigados:

Tabla 5- Distribución de la presencia femenina en los dos periodos de tiempo 1992-2006 respecto a la composición del grupo

\begin{tabular}{|c|c|c|c|c|c|c|}
\hline & & Solitario & Niña-niña & Mixto & Grupo con adulto & Grupo chicas \\
\hline \multirow{2}{*}{ LOGSE } & Frecuencia & 56 & 16 & 299 & 56 & 11 \\
\hline & $\%$ & $13 \%$ & $4 \%$ & $68 \%$ & $13 \%$ & $2 \%$ \\
\hline \multirow{2}{*}{ LOE } & Frecuencia & 37 & 22 & 334 & 45 & 9 \\
\hline & $\%$ & $8 \%$ & $5 \%$ & $75 \%$ & $10 \%$ & $2 \%$ \\
\hline
\end{tabular}

Fuente: Elaboración propia.

En la Tabla 6, se pueden observar algunos de los datos más significativos en referencia a los cambios que la representación femenina ha presentado en esas dos reformas legislativas, con respecto a la presencia femenina en cada familia instrumental por edad.

Tabla 6- Distribución de la presencia femenina en los dos periodos de tiempo 1992-2006 respecto a la representación de las familias instrumentales

\begin{tabular}{|c|c|c|c|c|c|c|c|c|c|}
\hline & & & $\begin{array}{l}\text { Viento- } \\
\text { madera }\end{array}$ & Viento-metal & Percusión & $\begin{array}{l}\text { Cuerda } \\
\text { frotada }\end{array}$ & $\begin{array}{c}\text { Cuerda } \\
\text { percutida }\end{array}$ & Voz & $\begin{array}{l}\text { Cuerda } \\
\text { pulsada }\end{array}$ \\
\hline \multirow{4}{*}{ LOGSE } & \multirow{2}{*}{ Niñas } & Frecuencia & 64 & 5 & 156 & 8 & 7 & 92 & 9 \\
\hline & & $\%$ & $19 \%$ & $1 \%$ & $46 \%$ & $2 \%$ & $2 \%$ & $27 \%$ & $3 \%$ \\
\hline & \multirow{2}{*}{ Mujeres } & Frecuencia & 6 & 8 & 15 & 24 & 4 & 33 & 7 \\
\hline & & $\%$ & $6 \%$ & $8 \%$ & $15 \%$ & $25 \%$ & $4 \%$ & $34 \%$ & $7 \%$ \\
\hline \multirow{4}{*}{ LOE } & \multirow{2}{*}{ Niñas } & Frecuencia & 42 & 9 & 110 & 8 & 11 & 125 & 2 \\
\hline & & $\%$ & $14 \%$ & $3 \%$ & $36 \%$ & $3 \%$ & $4 \%$ & $41 \%$ & $1 \%$ \\
\hline & \multirow{2}{*}{ Mujeres } & Frecuencia & 11 & 5 & 13 & 16 & 7 & 83 & 5 \\
\hline & & $\%$ & $8 \%$ & $4 \%$ & $9 \%$ & $11 \%$ & $5 \%$ & $59 \%$ & $4 \%$ \\
\hline
\end{tabular}

Fuente: Elaboración propia. 
Se han observado disminuciones y aumentos significativos: en primer lugar, las instrumentistas de viento-madera representadas en la LOGSE han disminuido respecto a la LOE, en cuanto al grupo de menores, que no de adultos (18,8\% frente a 13,7\%.); en segundo lugar, han disminuido el número de representadas de cuerda pulsada, cuerda frotada y percusión, pero, ha aumentado en cuanto a viento-metal, cuerda percutida y voz. Mientras que las jóvenes estudiantes con instrumentos de cuerda frotada han aumentado, no ha sucedido lo mismo con las adultas: 24,7\% frente a 11,4\%. En cuanto a la cuerda pulsada (guitarras), también se observa una disminución en la representación, de niñas y mujeres adultas. Ahora bien, aunque pueda hablarse de más representaciones femeninas con instrumentos de esta familia, es cierto que se ha producido una disminución significativa de niñas y adultas: 45,7\%-35,8\% en niñas y 15,5\%-9,3\% en adultas (Tabla 7).

La Tabla 5 recoge algunos ejemplos, a modo de colofón de los resultados obtenidos, de los distintos instrumentos con que han sido representadas las niñas-mujeres de las imágenes analizadas:

Tabla 7- Ejemplos Distribución de la presencia femenina en los dos periodos de tiempo 1992-2006 respecto a la representación de los instrumentos musicales

\begin{tabular}{|c|c|c|c|c|c|c|c|c|c|c|c|c|c|c|c|}
\hline & & & Batería & Bombo & Trombón & Piano & Violonchelo & Caja & Timbales & $\begin{array}{l}\text { Guitarra } \\
\text { eléctrica }\end{array}$ & Guitarra & $\begin{array}{l}\text { Guitarra } \\
\text { clásica }\end{array}$ & Contrabajo & Voz & Saxofón \\
\hline \multirow{4}{*}{$\begin{array}{l}\text { 嵌 } \\
\text { O }\end{array}$} & \multirow{2}{*}{ 蛋 } & $\mathrm{F}$ & - & 5 & 1 & 6 & 3 & 9 & 3 & - & 1 & 1 & 2 & 92 & 2 \\
\hline & & $\%$ & - & $1.5 \%$ & $0.3 \%$ & $1.8 \%$ & $0.9 \%$ & $2.6 \%$ & $0.9 \%$ & - & $0.3 \%$ & $0.3 \%$ & $0.6 \%$ & $27 \%$ & $0.6 \%$ \\
\hline & \multirow{2}{*}{ 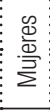 } & $\mathrm{F}$ & - & 1 & 2 & 4 & 3 & 2 & 1 & - & 1 & 2 & 2 & 33 & 1 \\
\hline & & $\%$ & - & $1 \%$ & $2.1 \%$ & $4.1 \%$ & $3.1 \%$ & $2.1 \%$ & $1.0 \%$ & - & $1 \%$ & $2.1 \%$ & $2.1 \%$ & $34 \%$ & $1 \%$ \\
\hline \multirow{4}{*}{ 岁 } & \multirow{2}{*}{ 胥 } & $\mathrm{F}$ & 2 & 1 & 3 & 7 & - & 2 & - & 2 & - & - & - & 125 & 4 \\
\hline & & $\%$ & $0.7 \%$ & $0.3 \%$ & $1 \%$ & $2.3 \%$ & - & $0.7 \%$ & - & $0.7 \%$ & - & - & - & $40.7 \%$ & $1.3 \%$ \\
\hline & \multirow{2}{*}{$\frac{\mathscr{D}}{\frac{\mathscr{d}}{0}}$} & $\mathrm{~F}$ & 2 & - & - & 3 & 8 & 1 & - & 3 & - & 1 & - & 83 & 2 \\
\hline & & $\%$ & $1.4 \%$ & - & - & $2.1 \%$ & 5.7 & $0.7 \%$ & - & $2.1 \%$ & - & $0.7 \%$ & - & $59.3 \%$ & $1.4 \%$ \\
\hline
\end{tabular}

Fuente: Elaboración propia.

\section{Discusión de resultados}

En el curso 1991/1992, durante la LOGSE, se contaba con 85.361 maestros y 196.385 maestras; y, en el curso 2006/2007, durante la LOE, las maestras representaban 230.288 frente a 64.152 hombres. Actualmente, los datos presentados por el Instituto Nacional de Estadística del curso 2016/2017 (INE, 2016), muestran cómo hay más maestras que maestros. Entonces, ¿por qué esta realidad no terminó de reflejarse en los libros de texto musicales? Loizaga (2005) considera que la denominada Tercera Ola o de Estudios de Género ha llegado con retraso al ámbito educativo musical: esta figura del músico instrumentista en los manuales había estado destinada, mayoritariamente, al género masculino en la LOGSE; de hecho, no se observó un incremento tan importante de la 
presencia femenina durante la LOE (Tabla 5), a pesar de la realidad educativa comentada. Esto también viene de la mano de la escasez de investigaciones sobre género y educación musical que, en nuestro país, no fueron tan numerosas durante la última década del siglo XX como en otros países (ABELES; PORTE, 1978; GRISWOLD; CHROBACK, 1981; KOZA, 1992, 1994; ZERVOUDAKES; TANUR, 1994), desarrollándose en mayor número durante este nuevo siglo XXI (DIGÓN-REGUEIRO, 2000; VIÑUELA, 2011; VALDEBENITO, 2013; LÓPEZ-NAVAJAS, 2014; HIDALG0, 2016).

Los resultados han mostrado una tendencia al cambio para tratar de reflejar esa realidad, pero no en la medida que debería, en consonancia con la investigación de Sadeq (2016) en Jordania: han mostrado una tendencia al alza (Tabla 6), en cuanto a las representaciones femeninas con instrumentos de viento-metal y de cuerda percutida, tal como puede verse en estudios anteriores de Hidalgo (2016) y que han venido a confirmar ese cambio lento, pero sin parada, que ya anunciaba Máñez (2015); aunque, no deja por ello de adolecerse de esta situación de retraso que los materiales presentan respecto a la mayor presencia real de la mujer en la práctica instrumental actual (ALMENAR, 2012). Es decir, pongamos por ejemplo que, si bien la voz pueda tener esa tradición femenina, las familias de viento-metal y de cuerda percutida, no, lo que muestra el reflejo del cambio social de finales del siglo XX al XXI representados por la LOGSE y la LOE en los materiales analizados, respectivamente.

Frente a otras investigaciones centradas en el análisis de las imágenes para detectar la presencia de la mujer como compositora o intérprete de prestigio y en cuanto a clichés/ estereotipos, destaca el estudio realizado por Cambero y Guerrero (2014), que analizaron los libros de $5^{\circ}$ y $6^{\circ}$ curso de Everest, SM, Anaya, Santillana y Alhambra, con resultados similares. Sin embargo, nuestro estudio, que ha pretendido realizar un análisis de los materiales destinados a la educación musical atendiendo a la perspectiva de género, en la línea de la crítica de las corrientes academicistas tradicionales postulada en la Tercera Ola (LOIZAGA, 2005), ha puesto de manifiesto un cambio en la representación femenina con determinados instrumentos habituales del intérprete masculino, lo que permite señalar cierto avance en la igualdad de género.

Se han contabilizado 438 mujeres representadas en los materiales LOGSE, frente a las 447 de la LOE. Datos tan poco significativos no deben suponer una pérdida de interés, ya que, se han producido cambios en cuanto a la tipología de los instrumentos utilizados por las féminas, apreciándose cambios significativos en los resultados obtenidos. Esto supondría acercarse a la desaparición de los arquetipos tradicionales masculinosfemeninos que indicaban Pellejero y Torres (2011) como todavía presentes en nuestros materiales. Debe señalarse que, a pesar de que esta investigación se ha centrado en cuantificar la presencia femenina en los libros de texto musicales, se ha cuantificado también la masculina como instrumento de comparación: si bien, podría considerarse un avance que la mujer aparezca representada con instrumentos de viento-metal, si el hombre aparece con la batería (instrumento de gran peso para el control rítmico) no puede considerarse tan relevante el cambio porque el trombón es un instrumento más acompañante que melódico.

Debe señalarse que los resultados más interesantes estuvieron relacionados con el aumento de la figura femenina como instrumentista de viento-metal, de cuerda percutida (piano) y de voz. Así, los instrumentos grandes y pesados que implican mayor fuerza física 
se asociaron tradicionalmente al género masculino porque se consideró que la fuerza física de la mujer era menor. Los agrupamientos mixtos (niño-niña) con instrumentos de viento-metal, muestran a niñas tocando trombones y a niños tocando violonchelos, cuando tradicionalmente ambos instrumentos hubieran estado representados con figuras masculinas. En este sentido, puede observarse cómo iría disminuyendo ese discurso androcéntrico que Hawkins (2007) ha señalado presente en los libros de texto desde los años sesenta.

Los instrumentos de cuerda percutida también eran más habituales asociados a niños. Las imágenes analizadas han mostrado un incremento de niñas con este instrumento, sobre todo, cuando las agrupaciones de cámara son mixtas y los otros instrumentos representados son más pesados-grandes (tocados por niños). La guitarra parece seguir siendo un feudo masculino, dado que el número de hombres representados es considerablemente mayor que el de las mujeres, en LOGSE y LOE.

Los instrumentos de la familia de viento-metal, sobre todo la tuba, requieren una importante presión de la columna de aire y presencia física, lo que llevó a su tradicional especialización por parte de los varones, como muestran las investigaciones de Sansaloni (2017), donde el 90\% de estos tocan instrumentos de viento-metal; aunque en las imágenes analizadas la mujer aparece ya con este instrumento, así, viene a recogerse la realidad mostrada por Almenar (2012): un 47\% de los miembros de las bandas son mujeres. Aunque antes no era habitual encontrarse con tantas féminas en las agrupaciones musicales y, por tanto, en las representaciones, como han señalado autores anteriores (KOZA, 1992, 1994; DIGÓN-REGUEIRO, 2000).

En cuanto al canto, Koza (1992) revelaba en sus investigaciones que estaba considerada una actividad tradicionalmente femenina: la investigación del período legislativo analizado (LOGSE-LOE) ha venido a confirmar este hecho y a mostrar una tendencia al alza, tanto en niñas como en mujeres adultas. Loizaga (2005) ha señalado que, en este caso, puede hablarse más bien de hombres ausentes, aunque esta temática se alejaría de los objetivos de la presente investigación.

Dentro de la percusión, hay instrumentos que requieren una considerable destreza óculo-manual y que también van ganándose la representación con niñas-mujeres entre los dos períodos analizados. La percusión había estado tradicionalmente vinculada al universo masculino (KOZA, 1992, 1994) como ya señaló Cabanes (2008) al afirmar que hay una tradición sociocultural sexista en cuanto al uso de determinados instrumentos de mayor peso y destreza, vinculados durante siglos al varón: antes de la LOGSE, no se podía hablar de representaciones femeninas con instrumentos de percusión (DIGÓN-REGUEIRO, 2000), así que, el cambio ha sido significativo porque ha pasado de no contarse con mujeres percusionistas a contarse con algunas. Los instrumentos de percusión más grandes (timbales y bombos), tradicionalmente masculinos, tienen una importante presencia femenina en la LOGSE, como hemos comprobado; situación similar encontramos en los instrumentos propios de las bandas, como la caja y el bombo (en algunas imágenes analizadas, las niñas aparecen tocando cajas y los niños los bombos, más pesados). Con todo, cuando aparecían en grupos de cámara, éstos mostraban a las chicas tocando los bombos.

El discurso en los libros de texto parece coincidir en las distintas editoriales: se representan indistintamente niños-niñas $\mathrm{u}$ hombres-mujeres con unos instrumentos $\mathrm{u}$ 
otros, pero cuando están en agrupaciones camerísticas el instrumento más complejopesado-grande recae en manos masculinas. Es importante el hecho de que aumente el número de mujeres trompetistas, pero no puede considerarse del todo relevante si en esa agrupación mixta aparece el hombre tocando la batería, instrumento que dirige la actuación y requiere una importante destreza óculo-manual.

\section{Conclusiones}

Atendiendo a los objetivos, se ha llegado a las conclusiones que se exponen seguidamente. De acuerdo con su objetivo principal, centrado en estudiar la representación de la mujer instrumentista en los libros de texto de las principales editoriales valencianas, se ha podido comprobar que, los datos obtenidos confirman que todavía queda mucho camino por recorrer: las editoriales deben respetar los principios básicos de la igualdad interpersonal, de capacidades intelectuales y socioemocionales. Así, ese aprendizaje subliminal del bombardeo de imágenes podrá reorientarse hacia una igualdad de género real y efectiva en la microsociedad del alumnado. Debe conseguirse una relectura del discurso educativo musical (LOIZAGA, 2005), en el cual las imágenes contribuyan a reforzar el respeto a la identidad y a la diferencia (RAMOS LÓPEZ, 2003).

A nivel secundario, su objetivo centrado en mostrar la evolución de la mujer en determinados instrumentos de tradición masculina ha permitido conocer el pequeño avance conseguido por las féminas, que han visto cómo empezaban a ser representadas con trompetas o con instrumentos de percusión. En este sentido, la investigación centrada en la asignación de roles y la construcción de identidades, otro de los principales ámbitos de investigación de los estudios de género desde la educación musical (LOIZAGA, 2005), tiene gran importancia en la formación del individuo (MARTIN VICARI, 2015). Debe señalarse que, a pesar de lo interesante y determinante de esta temática investigada para la educación en igualdad, en España, son bastante escasas las investigaciones sobre géneroinstrumento musical en los libros de texto de EP. Esto lleva a considerar lo realmente necesario que es revisar las representaciones humanas en los libros de texto musicales para que pueda producirse lo que Loizaga (2005) vino a denominar la relectura del discurso educativo musical. Solo de esta manera podrá empezar a hablarse de un discurso de igualdad real dentro y fuera del ámbito educativo, y dentro y fuera de los libros de texto, convirtiéndola en una realidad para la sociedad española.

Otro objetivo secundario se ha centrado en comprender los motivos que han podido determinar la evolución mayor o menor de dichas representaciones femeninas. En este sentido, de acuerdo con lo expuesto por Loizaga (2005) en los postulados investigadores de los estudios de género en la educación musical centrados en el proceso de enseñanza/aprendizaje, el libro de texto sigue poniendo de manifiesto la baja y estereotipada representación femenina en las actividades musicales. Por tanto, aunque los datos obtenidos permitan hablar de cierto incremento, continúa sin ser suficientemente representativo como para poder hablar de un cambio con mayúsculas para la figura de la mujer. Podría relacionarse esto con lo que Hidalgo (2016) ha venido a denominar un mecanismo invisible de refuerzo de desigualdades (culturales, en su caso), pero cuya idea 
podrá reorientarse, reutilizarse, orientando el uso de las imágenes en los libros de texto de Música hacia una igualdad de género real y efectiva en la microsociedad del alumnado.

\section{Referencias}

ABELES, Harold; PORTER, Susan Yamk. The sex-stereotyping of musical instruments. Journal of Research in Music Education, Evanston, v. 26, n. 2, p. 65-75, 1978. https://doi.org/10.2307/3344880

ALMENAR, Pilar. La música: femenina y singular. El País, Madrid, ago. 2012. Disponible en: https://elpais. com/ccaa/2012/08/26/valencia/. Acceso en: 27 jun. 2019.

ÁLVAREZ, Antonio (coord.). Compositoras españolas: la creación musical femenina desde la Edad Media hasta la actualidad. Madrid: Centro de Documentación de Música y Danza; Inaem, 2008.

AYALA, Isabel María. Música y municipio: marco normativo y administración de las bandas civiles en España (1931-1986). Estudio en la provincia de Jaén. Granada: Universidad de Granada, 2013.

CABANES, Aránzazu. Instrumentos musicales y género. Alicante: Universidad de Alicante, 2008.

CARRETERO, Santiago. Ministerio de Igualdad: objetivos claros ante un problema de competencias. Actualidad administrativa, Madrid, n. 1, p. 1, 2009.

CERRÓN, María Teresa; COBANO-DELGADO, Verónica. El papel de la mujer en las imágenes de los libros de texto de educación primaria: estudio comparado entre España y Marruecos. Educatio Siglo XXI, Murcia, v. 27, n. 1, p. 231-248, 2009.

CLARES, Esperanza. Bandas y música en la calle: una visión a través de la prensa en las ciudades de Murcia y Cartagena (1800-1875). Revista de Musicología, Madrid, v. 28, n. 1, p. 543-562, 2005. http:// dx.doi.org/ 10.2307/20798088

CONWAY, Colleen. Gender and musical instrument choice: a phenomenological investigation. Bulletin of the Council for Research in Music Education, Illinois, n. 146, p. 1-17, 2000.

DEL RÍ0, Dionisio. Métodos de investigación en educación. Madrid: UNED, 2003.

DÍAZ, María Teresa. La perspectiva de género en la formación del profesorado de música. Reice, Madrid, v. 3, n. 1, p. 570-577, 2005.

DIGÓN-REGUEIRO, Patricia. An analysis of gender in a Spanish music textbook. Music Education Research, London, v. 2, n. 1, p. 57-73, 2000. https://doi.org/10.1080/14613800050004431

ESPAÑA. Jefatura de Estado. Ley Orgánica 8/1985, de 3 de julio, reguladora del Derecho a la Educación. Boletín Oficial del Estado, Madrid, n. 159, ref. 12978, p. 21015-21022, 4 julio 1985.

ESPAÑA. Jefatura de Estado. Ley Orgánica 1/1990, de 3 de octubre, de Ordenación General del Sistema Educativo. Boletín Oficial del Estado, Madrid, n. 238, ref. 24172, p. 28927-28942, 4 oct. 1990. 
ESPAÑA. Jefatura de Estado. Ley Orgánica 2/2006, de 3 de mayo, de Educación. Boletín Oficial del Estado, Madrid, n. 106, ref. 7899, p. 17158-17207, 4 mayo 2006.

FERNÁNDEZ, Francisco. Obstáculos percibidos por el profesorado de educación musical en los libros de texto. Investigación en la Escuela, Sevilla, n. 65, p. 49-57, 2008.

GALLEGO, Cristina Isabel. Análisis comparativo de proyectos editoriales nacionales respecto al desarrollo de las enseñanzas mínimas de música y conocimiento del entorno en el segundo ciclo de educación infantil. Málaga: Universidad de Málaga, 2015.

GLEICHAUF, Ingeborg. Mujeres filósofas en la historia: desde la Antigüedad hasta el siglo XXI. Madrid: Icaria, 2010.

GODALL, Pere; ANDREU, María. La música integrada en el currículo de primaria y la adquisición de competencias básicas. Aula de Innovación Educativa, Barcelona, n. 190, p. 16-20, 2010.

GÓMEZ-PINTADO, Ainhoa; MARCELLÁN, Idoia. ¿Responden las imágenes utilizadas en educación plástica visual a la propuesta curricular? Un análisis de las imágenes de los libros de texto de educación secundaria en la Comunidad Autónoma Vasca. Educación XXI, Madrid, v. 20, n. 1, p. 233-252, 2017. https://doi. org/10.5944/eduXX1.17510

GONZÁLEZ, Alba; TÁBOAS, María Inés; REY, Ana. Los libros de texto como herramientas para la promoción de una práctica físico-deportiva en igualdad: análisis comparativo de la representación racial entre los libros publicados durante la vigencia de la LOGSE y la LOE. Cuadernos de Psicología del Deporte, Murcia, v. 10, p. 31-36, 2010.

GRISWOLD, Philip; CHROBACK, Denise. Sex-role associations of music instruments and occupations by gender and major. Journal of Research in Music Education, Evanston, v. 29, n. 1, p. 57-72, 1981. https://doi.org/10.2307/3344680

HAWKINS, Patrick. What boys and girls learn through song: a content analysis of gender traits and sex bias in two choral classroom textbooks. Research and Issues in Music Education, Harrisonburg, v. 5, n. 1, p. 1-8, 2007.

HERNÁNDEZ, Nieves. Educación musical y proyección laboral de las mujeres en el siglo XIX: el Conservatorio de Música de Madrid. Revista Transcultural de Música (Sibetran), Lisboa, n. 15, p. 1-42, 2011.

HIDALGO, Manuel. ¿Han evolucionado los libros de texto? Análisis comparativo del Medioevo en manuales escolares del siglo XX y XXI. Clío, Zaragoza, n. 40, p. 1-34, 2014.

HIDALGO, María Belén. Más allá del rosa o azul: análisis de la construcción de la identidad desde una perspectiva de género a través de la educación musical en la etapa de primaria. Huelva: Universidad de Huelva, 2016.

HSIEH, Hsiu-Fang; SHANNON, Sarah. Three approaches to qualitative content analysis. Qualitative Health Research, Utah, v. 15, n. 9, p. 1277-1288, 2005. https://doi.org/10.1177/1048732305276687 
INE. Instituto Nacional de Estadística. Las cifras de la educación en España: estadísticas e indicadores. Madrid: Ministerio de Educación, Cultura y Deporte, 2016.

KOZA, Julia Eklund. The boys in the Band: sexism and the construction of gender in middle school textbook illustrations. Journal of Research in Music Education, Evanston, v. 6, n. 3, p. 85-103, 1992.

KOZA, Julia Eklund. Females in 1988 middle school music textbooks: an analysis of illustrations. Journal of Research in Musiv Education, Evanston, v. 42, n. 2, p. 145-171, 1994. https://doi.org/10.2307/3345498

LANDIS, Richard; KOCH, Gary. The measurement of observer agreement for categorical data. Biometrics, Denver, n. 33, p. 159-174, 1977. http://doi.org/10.2307/2529310

LOIZAGA, María. Los estudios de género en la educación musical: revisión crítica. Musiker, San Sebastián, n. 14, p. 159-172, 2005.

LÓPEZ-NAVAJAS, Ana. Análisis de la ausencia de las mujeres en los manuales de la ESO: una genealogía del conocimiento ocultada. Revista de Educación, Madrid, n. 363, p. 282-308, 2014.

LÓPEZ-NAVAJAS, Ana; QUEROL, María. Las escritoras ausentes en los manuales: propuestas para su inclusión. Didáctica. Lengua y Literatura, Madrid, n. 26, p. 217-240, 2014. https://doi.org/10.5209/ rev_DIDA.2014.v26.46840

MÁÑEZ, Eva. Avanzando al compás. In: ESCOLAR, Arsenio (dir.). Bandas de música de la Comunitat Valenciana. Madrid: 20 Minutos, 2015. p. 28-29.

MARTíN VICARI, Pablo. De la monodia patriarcal a la polifónica de género: nuevas perspectivas para la planificación didáctica de la enseñanza de la música. In: BACH, Ana María (coord.). Para una didáctica con perspectiva de género. Buenos Aires: Miño y Dávila, 2015. p. 235-268.

MAS, Juan Vicente. Valencia, certamen de bandas de música: país Musical. Ritmo, Madrid, v. 49, n. 492, p. 88, 1979.

MORALES, Ángela. La educación musical en primaria durante la LOGSE en la Comunidad de Madrid. Revista de Psicodidáctica, Vizcaya, n. 17, p. 109-116, 2004.

MOYA, Irene et al. Estereotipos de sexo y raza en las imágenes de los libros de texto de educación física en primaria. Retos, Murcia, n. 23, p. 14-18, 2013.

MUÑOZ, María Pilar. Mujeres españolas en las artes plásticas. Madrid: Síntesis, 2004.

NAVIA, Pedro et al. Incidencia y factores de riesgo de dolor cervical en músicos de orquestas españolas. Mapfre Medicina, Madrid, v. 18, n. 1, p. 27-35, 2007.

NEUENDORF, Kimberly. Content analysis - A methodological primer for gender research. Sex Roles, Kent, v. 64, n. 3-4, p. 276-289, 2011. http://doi.org/10.1007/s11100-010-9893-0 
OLIVER, José Salvador. Les bandes de música: senyal d'identitat del poble valencià. Revista Valenciana D'estudis Autonòmics, Valencia, v. 58, n. 2, p. 42-71, 2013.

OYA, Laura; HERRERA, Lucía. Factores determinantes de la elección del instrumento musica: una revisión de la literatura. Dedica, Granada, n. 4, p. 269-287, 2013.

PARRA, Juan. Educación en valores y no sexista. Castilla La Mancha: Instituto de la Mujer, 2009.

PELLEJERO, Lucía; TORRES, Blanca. La educación de la sexualidad: el sexo y el género en los libros de texto de Educación Primaria. Revista de Educación, Madrid, n. 354, p. 399-427, 2011.

PERALTA, Miquel. Josepa Cucó, Antonio Ariño, Isabel de la Cruz, Pilar Luz y Fernando Ros: músicos y festeros valencianos. Trans, Lisboa, n. 1, p. 1, 1995.

PÉREZ, Toni. El mercado editorial: producción y comercialización de los libros de texto. Kikiriki, Sevilla, n. 61, p. 30-38, 2001.

PRENDES, María Paz. Las imágenes en los libros de texto. Comunicación y Pedagogía, Madrid, n. 151, p. 101-108, 1998.

PRO, Carlos de; PRO, Antonio de. ¿Qué estamos enseñando con los libros de texto? La electricidad y la electrónica de Tecnología en $3^{\circ}$ ESO. Revista Eureka sobre Enseñanza y Divulgación de las Ciencias, Cádiz, v. 8, n. 2, p. 149-170, 2011.

RAMOS LÓPEZ, Pilar. Feminismo y música. Madrid: Narcea, 2003.

REMNANT, Mary. Historia de los instrumentos musicales. Barcelona: Robinbook, 2002.

RODRÍGUEZ, Carmen (coord.). La ausencia de las mujeres en los contenidos escolares. Buenos Aires: Miño y Dávila, 2004.

SADEQ, Nasiema Mustafa. The image of women in the national education textbooks in Jordan. Journal of Education and Practice, India, v. 7, n. 16, p. 97-107, 2016.

SANSALONI, María del Carmen. Presencia de estereotipos de género en la elección de especialidad musical profesional. Valencia: Asociación Valenciana de Musicología, 2017. Disponible en: http://avamus. org/es/presencia-de-estereotipos-de-genero-en-la-eleccion-de-especialidad-musical-profesional/. Acceso en: 27 jun. 2019.

SIMÓN, María del Carmen. Mil estudios actuales sobre escritoras del siglo XX. Bibliografía. Arbor, Madrid, v. 721, n. 182, p. 661-703, 2006. http://doi.org/10.3989/arbor.2006.i721.60

SHOCKER, Jessica; WOYSHNER, Christine. Representing African American women in U.S. history textbooks. The Social Studies, Canadá, v. 104, n. 1, p. 23-31, 2013. https://doi.org/10.1080/00377996.2012.65 5346 
TERRÓ, María Teresa; COBANO-DELGADO, Verónica. El papel de la mujer en las ilustraciones de los libros de texto de educación primaria. Foro de Educación, Salamanca, n. 10, p. 385-400, 2008.

VAILLO, María. La investigación sobre libros de texto desde la perspectiva de género: ¿hacia la renovación de los materiales didácticos? Tendencias Pedagógicas, Madrid, n. 27, p. 97-124, 2016. http://doi. org/10.15366/tp2016.27.003

VALDEBENITO, Lorena. Educación musical y género: una perspectiva inclusiva desde el currículum de aula. Revista Neuma, Talca, v. 6, n. 2, p. 58-66, 2013.

VALLS, Rafael. Las imágenes en los manuales escolares de Historia y las dificultades de su uso didáctico. Clío \& Asociados, Santa Fe, n. 11, p. 11-23, 2007.

VIÑUELA, Eduardo. La subversión de los roles de género en la música popular: Mónica Naranjo como artista inapropiada/ble. Música y Estudios Sobre las Mujeres, Madrid, n. 15, p. 1-20, 2011.

WIELAND, Sondra. A historical view of woman and music education careers. Philosophy of Music Education Review, Indiana, v. 17, n. 2, p. 163-184, 2009.

ZERVOUDAKES, Jason; TANUR, Judith. Gender and musical instruments: winds of changes? Journal of Research in Music Education, Evanston, v. 42, n. 1, p. 58-67, 1994. https://doi.org/10.2307/3345337

Recibido en: 08.04.2020

Revisado en: 30.06 .2020

Aprobado en: 04.08.2020

María del Mar Bernabé Villodre es doctora en Teoría e Historia de la Educación y titulada en Pedagogía del Lenguaje y la Educación Musical. Sus intereses investigadores están centrados en la educación a la diversidad desde el aula musical.

Desirée García Gil es doctora en Historia y Ciencias de la Música (Mención Europea) y titulada en Educación Musical. Sus intereses investigadores están centrados en la educación musical desde una perspectiva de género.

Vladimir Martínez Bello es doctor en Ciencias de la Actividad Física y Deportiva y titulado en Ciencias de la Actividad Física y Deportiva. Sus intereses investigadores están centrados en la actividad física en el alumnado de Educación Infantil desde una perspectiva de género. 